\title{
Evaluation of the physical activity level of the soldiers of the Kinshasa Garrison: Cross-sectional and observational study
}

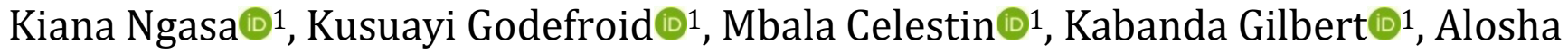 \\ Nkodila@2, Teddy Bofosa®1, Katosia Lusenge Willy®1, Nkiama Constant@1 \\ ${ }^{1}$ Laboratory Cardiovascular Exploration Center of the Military Health Service of the Armed Forces of the Democratic Republic of Congo. \\ 2 University Clinics of Kinshasa, Democratic Republic of Congo.
}

\begin{abstract}
A high level of physical activity helps soldiers to fight against many chronic non-communicable pathologies. The aim of the study was to measure the level of physical activity (PA) of soldiers of the Armed Forces of the Democratic Republic of Congo in Kinshasa, aged 19 to 69. This is a cross-sectional and observational study with a questionnaire survey. It was conducted in the Garrison of Kinshasa where cardiovascular exploration center of the bodies in military health served us as the pilot point, which constituted a convenience sample of 899 soldiers who took part in our survey. The data collection was carried out by a self-questionnaire integrating the Physical Activity Readiness Questionnaire (PAR-Q) score of a short version, which informed the practice of physical activity and assessed the usual daily activities, the time spent sitting at work, the use of usual health routes. The study was conducted in the garrison of Kinshasa between October 2020 and February 2021 where all categories of army rank: corporals and soldiers, non-commissioned officers, junior officers, senior officers, aged 19 to 69 years, took part in this study. A total of 899 soldiers responded to the questionnaire, consisting of 797 men and 102 women, $88.7 \%$ vs $11.3 \%$. The mean age was $45.4 \pm 11.9$ years and the mean physical activity scores were significantly different according to age and rank ( $\mathrm{p}=0.007)$ of soldiers aged 19 to 69 years. It is shown that most of the military were inactive (54.2\%) versus $45.8 \%$ were active. Of the active members, $34.3 \%$ were slightly active, $8.5 \%$ moderately active and $3.1 \%$ very active. The age of the physical inactivity level increased significantly with the chronological age of the soldier $(\mathrm{p}=0.045)$. This physical inactivity was significantly higher among privates \& corporals and NCOs ( $\mathrm{p}=0.003)$. Military personnel with a morbid history had a significantly higher frequency of physical inactivity $(\mathrm{p}=0.046)$. This study reveals that the majority of Kinshasa soldiers have a low level of physical activity. This low level of PA exposes them to develop chronic non-communicable pathology. It is suggested that a military PA program be proposed to them so that they improve their PA level.
\end{abstract}

Keywords. Activity level, military personnel, regular exercise.

\section{Introduction}

The high levels of physical activity (PA) are now considered a daily experience and an operational necessity to maintain the physical capabilities of men and women in uniform (World Health Organization, $2013 \mathrm{~b}$ ). The regular practice of military physical activities has become a public health issue (Maire et al., 2002). This last one has become an operational necessity and a corporal expression, aiming to improve and to maintain the physical health of the military, considered as one of the basic foundations of an armed force or the African armies do not grant importance, because of the technological progress not leaving a place to the training physical military (EPM) or other sports requiring the physical efforts, responsible for the no communicable chronic diseases (Pobee et al., 1977; Manton et al., 1988).

The Directorate General of Military Health Service of the Armed Forces of the Republic of Congo conducted a study in the Garrison of Kinshasa in 2008 and 2009 , which confirms that more than $45 \%$ of the Congolese military were inactive and this would lead to serious consequences on their physical health (World Health Organization, 2010). The observation is therefore clear to understand easily that their

\footnotetext{
\. Ngasa, e-mail: ngasa.nicaise@gmail.com

Received: September 25, 2021 - Accepted: October 06, 2021 - Published: October 10, 2021

To Cite: Ngasa, K., Godefroid, K., Celestin, M., Gilbert, K., Nkodila, A., Bofosa, T., Willy, K.L., \& Constant, N. (2021). Evaluation of the physical activity level of the soldiers of the Kinshasa Garrison: Cross-sectional and observational study. Turk J Kinesiol, 7(3), 92-97. DOI: $10.31459 /$ turkjkin.980591
} 
morphological profile of the Congolese military testifies without ambiguity the low level of practice of physical activity, leading to an inactive lifestyle with serious consequences of premature death of the military, this can be understood as easily on the abandonment of energy expenditure, which is one of the most common causes of cardiovascular disease with 17.5 million deaths in 2012 (3 out of 10 deaths) (Law \& Morris, 2009). This low level of physical activity is a risk factor for cardiometabolic diseases is also a threat to health. The World Health Organization states each year that there are more than 25 million deaths, are attributed to the low level of PA which is the cause of devastating effects on health (Gaylin \& Kates, 1997).

Numerous epidemiological studies have shown that regular physical activity is beneficial for the health of adults, but also children and adolescents (Jordan et al., 2008). The benefits are many and varied: Reduction in the morbidity and mortality of certain pathologies (cardiovascular diseases, respiratory diseases, cancer, obesity, traumas, and handicaps), maintenance and/or increase in physiological functions (muscular function, bone capital, endothelial function, immune system, cerebral functions, and nervous system, genetic factors of the response to training) and also in the quality of life (World Health Organization, 2013).

It has been observed that over a period of time, the Kinshasa military has adopted a sedentary behavior that is the gateway to chronic non-transmissible diseases, particularly hypertension and metabolic diseases (World Health Organization, 2009). This pilot study was conducted primarily to demonstrate the adverse effects of low levels of physical activity among the military in Kinshasa, the feasibility of which is detailed in the methodology.

\section{Methods}

This is an observational, cross-sectional study with the Physical Activity Readiness Questionnaire (PARQ) adapted to the Democratic Republic of Congo context measuring the physical activity level of military personnel in Kinshasa. The PAR-Q survey study used the September 2017 short version, measuring the physical activity level of adults and we interpreted it according to World Health Organization recommendations. The study took place in the garrison of Kinshasa, in the period from October 02 to February 05, 2021. The Garrison of Kinshasa is one of the most populated garrisons of the Armed Forces of the Democratic Republic of the
Congo where the command is within the headquarters of the military region of the camp lieutenant Kokolo, headed by a Brigadier General. A convenience sample was used to constitute the population of 899 military subjects, aged between 19 and 69 years, both sexes included of which 215 were corporals and soldiers, 345 were non-commissioned officers and 339 were officers. The convenience sample was constituted based on a letter of free and informed consent duly signed by military personnel from the Kinshasa garrison, voluntarily agreeing to participate in our study.

\section{Ethical Considerations}

All subjects voluntarily accepted to participate in this study according to Helsinki declarations. Before they participated in the study, they were informed about the study and taken a signed consent form. The study was approved by a local ethics committee with the number ESP/CE/151/2020.

\section{The Questionnaire Used to Measure Physical Activity Level}

We used the World Health Organization's survey questionnaire measuring PA level, PAR-Q version 2017. The questionnaire is divided into several levels: No PA, less than one hour per week, 1-2 hours per week regularly, 2-4 hours per week, more than 4 hours per week, time spent sitting in front of a computer or watching TV, type of PA practiced, minutes spent on average per week its physical activities, frequency practiced of its activities, the effort usually perceived during its physical activities, intensity of PA practiced at work, hours spent outside of work, minutes per day spent walking, and finally, number of floors on average climbed on foot each day. The intensity ranging from low, via moderate, intense, and very intense, from a frequency of once to more than four times a week whose rating is from 17 to 32 points was our reference to carry out our study. The PAR-Q questionnaire allowed us to calculate the 4 scores respectively rating the usual daily activity (work and commuting) between 1 and 5, the activity between 1 and 5 , the leisure activity between 1 and 5 , the global PA, sum of the three previous indexes between 3 and 15. This software not being free of right, in order to calculate these four scores, we calculated manually each score. Concerning the scores of daily activity and leisure time, for each question, we have noted each item from 1 to 5 corresponding to increasing activity. For example, for the question "During the day, you sit...." "Never" 
earned 1 point, "often 4 points, "sometimes" 3 points, "rarely", 2 points, and "never" 1 point. These scores were averaged over 5 by a rule of three. For the sports activity score, we multiplied by the number of hours of practice per week and then by the number of months of practice per month. A score of 1 was assigned to military personnel with a calculated nonzero score of fewer than 32 points. All military personnel who met the inclusion criteria and completed the questionnaire were included. The number of inclusions was limited by the 3-day questionnaire delivery time. A three-digit number was randomly assigned to each included soldier using a computer program: "Random Number Generator. The answers to these questionnaires were anonymized using this identification number. A validated scale determined the level of PA according to the less than 17 points, the soldier had a low level of PA, between 18 to 32 points the soldier had an active level of $P A$ and more than 32 points, the soldier had a very active level of activity (World Health Organization, 2017).

\section{Statistical Analysis}

Upon receipt of each questionnaire, the data were entered into the Excel software Epi info 6.0 and then analyzed using the Analysis function of this same software to operate the R software. The descriptive analyses represented the quantitative variables by their mean and standard deviation with their extremes in tables under the condition of normality of the distribution, otherwise by their median and interquartile range (EIQ interquartile range). Categorical variables were described in numbers and percentages. For univariate analyses, we essentially used the Chi-square test comparing categorical variables of dependent samples, when the number of participants was sufficient; otherwise, the Fisher test was used. The Welch's test compared the means of two independent samples of sufficiently large size, with different variances. It is an adaptation of the Student-test. When the normality assumption was not acceptable, the non-parametric Kruskal-Wallis test replaced it. The Bravais-Pearson linear correlation test was used to determine whether there was a significant linear relationship between two quantitative variables.

\section{Results}

\section{Military PA level}

It is shown that the majority of the members were inactive $(54.2 \%)$ vs. $45.8 \%$ declared active. Among the active members, we found $34.3 \%$ slightly active, $8.5 \%$ moderately active, and $3.1 \%$ very active (Figure 1).

\section{PA Level Score Assessment}

The comparison of score averages among military personnel by age and rank is shown in Figure 2. From the figure 1, it can be seen that the means of the PA level score (PAL) were significantly different by age $(\mathrm{t}=1.321 ; \mathrm{p}<0.01)$ and by military rank $(\mathrm{t}=0.974$; $\mathrm{p}<0.01$ ).

The level of PA of military personnel depended on chronological age. The average age of highly active soldiers was lower than the average age of inactive soldiers $(\mathrm{t}=1.653 ; \mathrm{p}=0.001)$.

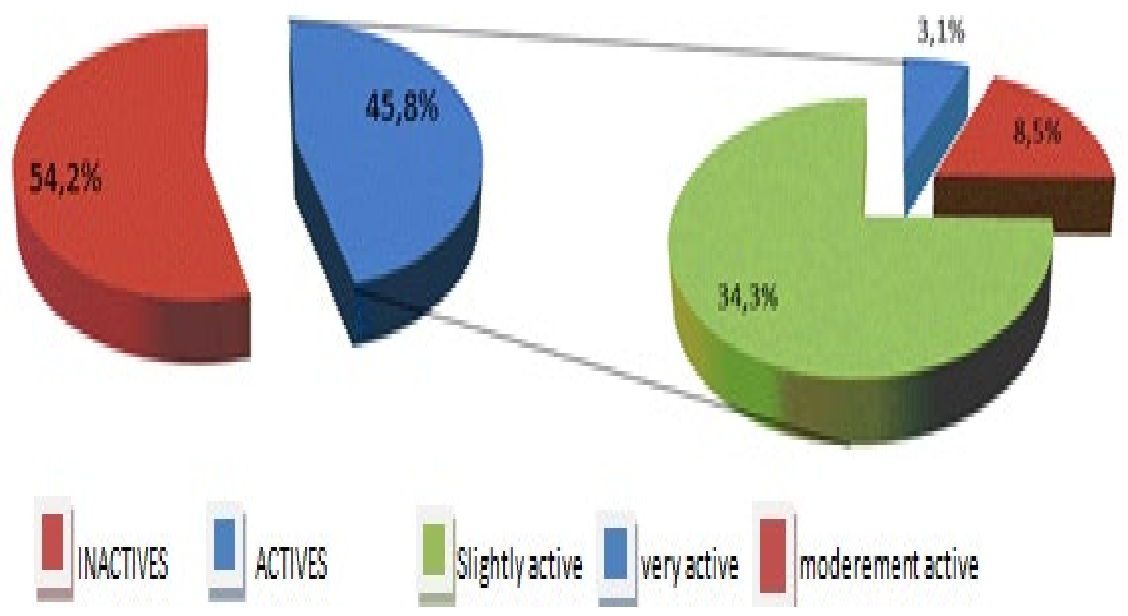

Figure 1. Military PA levels. 


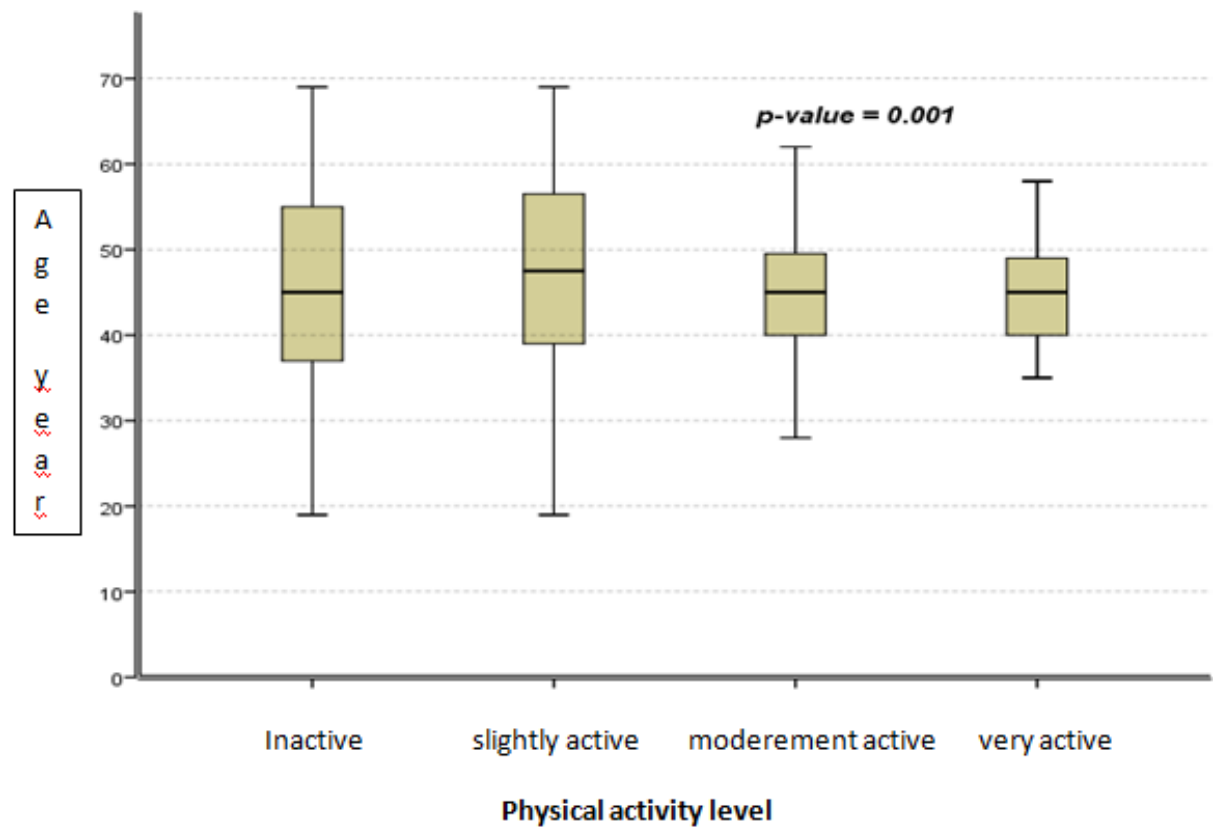

Figure 2. Average age comparison by military activity level.

\begin{tabular}{lcccccc}
$\begin{array}{l}\text { Table } 1 \\
\text { PA level of military personnel with health-related injuries. }\end{array}$ & \multicolumn{1}{l}{} \\
\hline \multirow{2}{*}{ Variables } & \multicolumn{1}{l}{ Inactive and sedentary } & Assets & Total & \\
\cline { 2 - 8 } & $\mathrm{n}$ & $\%$ & $\mathrm{n}$ & $\%$ & $\mathrm{n}$ & $\%$ \\
\hline High blood pressure & 100 & 11.1 & 84 & 9.3 & 194 & 20.4 \\
Diabetes mellitus & 30 & 3.3 & 23 & 2.5 & 53 & 5.8 \\
Obesity & 74 & 8.2 & 67 & 7.4 & 141 & 15.6 \\
Dyspnea on exertion & 30 & 3.3 & 24 & 2.6 & 54 & 6.0 \\
Asthma & 40 & 4.4 & 33 & 3.6 & 73 & 8.1 \\
Gonarthrosis & 50 & 5.5 & 42 & 4.6 & 92 & 10.2 \\
Low back pain & 63 & 7.0 & 48 & 5.3 & 111 & 12.3 \\
Alcoholism & 60 & 6.6 & 48 & 5.3 & 108 & 12.0 \\
Smoking & 40 & 4.4 & 43 & 4.7 & 83 & 9.2 \\
Heath History & 487 & 54.2 & 412 & 45.8 & 899 & 100 \\
\hline
\end{tabular}

Table 1 informs us that half of the military subjects were inactive, presenting then the morbid sanitary antecedents, $20.4 \%$ of High blood pressure, $5.8 \%$ of diabetics, $15.6 \%$ of obesity, $8.1 \%$ of asthmatics, $6.0 \%$ of dyspnea to the effort, $10.2 \%$ of gonarthrosis, $12.3 \%$ lumbago, $12.0 \%$ alcoholism and $9.2 \%$ of smokers of the cigarette. The latter almost damage the physical health, affecting especially the respiratory tract, the cardiovascular system and lead to musculoskeletal disorders in the military.

\section{Discussion}

The study was conducted in the garrison of Kinshasa militaries, assessed the level of blood pressure practice of Congolese military personnel using a WHO PAR-Q self-questionnaire. We observed low participation of women in both groups, $11.3 \%$ versus $88.7 \%$ (the ratio of gender: $8 \mathrm{M} / 1 \mathrm{~F}$ ). The study had involved 899 military personnel who responded to the questions. The level of PA of these soldiers is shown in Figure 1, which shows that the majority of soldiers were inactive (54.2\%) versus $45.8 \%$ considered active. Of the active members, $34.3 \%$ were slightly active, $8.5 \%$ were moderately active, 
and $3.1 \%$ were very active. The mean age was $45.4 \pm 11.9$ years (range 19-69 years). $38.4 \%$ were noncommissioned officers and $37.7 \%$ were officers. The majority of the soldiers had a high school education (69.4\%). It was noted that $57.5 \%$ had at least one history of illness. This distribution also varied according to the ranks: Corporals, privates, non-commissioned officers, and officers.

The level of PA of military personnel can play a very important role in the career of the soldier, however, it completely prevents NCDs, and improves the physical health of the military population. Interestingly, in a large cohort of nearly 792 men. Most of these studies in the world, for example in France with EPIML were devoted to cardio-metabolic diseases in the military such as the prevalence of overweight, obesity, and hypertension with $11.4 \%$ obesity in general: $9.3 \%$ have moderate obesity, $0.9 \%$ severe obesity and $0.4 \%$ morbid obesity. The weight gain over 5 years is $1.6 \mathrm{~kg}$ in 2003 and 2008 (United Nations, 2008). The U.S. Army has conducted several studies that had alarming results between 15 years, the figures were, even more, alarming with an average BMI of $29.1 \mathrm{~kg} / \mathrm{m}^{2}$ for men and $29.6 \mathrm{~kg} / \mathrm{m} 2$ for women. As for waist circumference, it increased from $99.1 \mathrm{~cm}$ to $102.1 \mathrm{~cm}$ for men and from $92.2 \mathrm{~cm}$ to $98.0 \mathrm{~cm}$ for women between 1999-2000 (Law \& Morris, 2009). In France, hypertensive patients had a rate that would probably approach $25 \%$ after the diagnosis was established, as indicated by the recommendations, by repeated blood pressure measurements, MAPA, or self-measurement (World Health Organization, 2008).

\section{Physical Activity Level}

The level of blood pressure of military personnel depended on chronological age. The average age of very active soldiers was lower than the average age of inactive soldiers $(p=0.001)$. We note that the majority of the soldiers were inactive $(54.2 \%)$ and $45.8 \%$ were active. Among the active members, $34.3 \%$ were slightly active, $8.5 \%$ moderately active and $3.1 \%$ very active.

\section{Physical Activity Level by Age Group and Grade}

The comparison of score averages among military personnel by age and rank is shown in Figure 1. From the figure, it appears that the means of the adapted physical activity score were significantly different according to age $(\mathrm{p}<0.01)$ and military rank $(\mathrm{p}=0.007)$. In Logistic Regression, the multivariate analysis had identified the factors associated with physical inactivity of the military in Table 3 . It shows that being a non-commissioned officer increased the risk of physical inactivity by 2 and having a university education reduced the risk of physical inactivity by 2 . Blood pressure level scores and quality of life were shown to be low in the total population and especially in men compared to women. Moreover, these two parameters are negatively correlated with the sociodemographic characteristics of the Congolese military.

A high prevalence of physical inactivity is commonly found in later studies (Cornillon et al., 2002; Dalal et al., 2011). Indeed, low levels of blood pressure are accompanied by an increase in the prevalence of physical inactivity, and this is related to the gain of fat mass (especially visceral) and the decrease in muscle mass which prevents the military from performing and increases sedentary behavior (Gnakamene et al., 2009).

\section{Health and Work Status}

Our results show that $57.5 \%$ of the soldiers had a morbid history and significantly high frequency of physical inactivity $(\mathrm{p}=0.046)$, and that physical inactivity increased with chronological age. The average age of the very active soldiers was lower than the age of the inactive soldiers ( $\mathrm{p}=0.001)$.

It is known that physical inactivity increases with age and with it weight gain and associated diseases. Thus, increased physical inactivity is now one of the strong risk factors for MCNT diseases (Psaty et al., 2003; Lakka et al., 1998). Indeed, the impact of physical activity on this type of disease has also been demonstrated in primary prevention in large populations. Thus, there is an inverse relationship between the level of PA and the risk of cardiovascular events in women (Shaper et al., 1969; United Nations, 2008). In addition, PA is also advocated during metabolic diseases such as diabetes (Feachem et al., 2002; Seedat et al., 1981).

As our results clearly show, diseases increase with physical inactivity. $100 \%$ of inactive military personnel suffer from chronic diseases. Thus, findings on the role of physical activity in disease prevention have led to recommendations to prescribe physical activity - along with drug treatment - with encouragement for health care professionals themselves to set an example in their lifestyle (Kearney et al., 2005). And this is clearly shown in our population, as military personnel are 
inactive, not in better physical health, and are very overweight.

\section{Conclusion}

This study reveals that the majority of Kinshasa soldiers have a low level of physical activity. This low level of physical activity exposes them to develop chronic non-communicable pathology. We suggest that a military physical activity program be proposed to them so that they improve their physical activity level.

\section{References}

Connor, M.D., Walker, R., Modi, G., \& Warlow, C.P. (2007). Burden of stroke in black populations in sub-Saharan Africa. Lancet Neurol, 6(3), 269-278.

Dalal, S., Beunza, J.J., Volmink, J., Adebamowo, C., Bajunirwe, F., Njelekela, M., Mozaffarian, D., Fawzi, W., Willett, W., Adami, H-O., \& Holmes, M.D. (2011). Noncommunicable diseases in sub-Saharan Africa: what we know now. Int J Epidemiol, 40, 4, 885-901.

Feachem, R.G.A., Kjellstrom, T., Murray, C.J.L., Over, M., \& Phillips, M.A. (eds). (1992). The health of adults in the developing world. New York: Oxford University Press.

Gaylin, D.S., \& Kates, J. (1997). Refocusing the lens: Epidemiologic transition theory, mortality differentials, and the AIDS pandemic. Soc Sci Med, 44(5), 609-621.

Gnakamene, J-B., Safar, M., \& Blacher, J. (2009). Traitementmédical de l'hypertensionartérielle. In Encyclopedie Médico-Chirurgicale (EMC). Elsevier Masson SAS: Paris.

Jordan, C.O., Slater, M., \& Kottke, T.E. (2008). Preventing chronic disease risk factors: rationale and feasibility. Medicina (Kaunas), 44(10), 745-750.

Kearney, P.M., Whelton, M., Reynolds, K., Muntner, P., Whelton, P.K., \& He, J. (2005). Global burden of hypertension: analysis of worldwide data. Lancet, 365(9455), 217-223.

Law, M.R., \& Morris, J.K. (2009). Use of blood pressure lowering drugs in the prevention of cardiovascular disease: meta-analysis of 147 randomized trials in the context of expectations from prospective epidemiological studies. BMJ, 338, b1665.

Maire, B., Lioret, S., Gartner, A., \& Delpeuch, F. (2002). Nutritional transition and non-communicable dietrelated chronic diseases in developing countries. Cahiers d'études et de recherches francophones, Santé, 12(1), 45-55.
Manton, K.G. (1988). The global impact of noncommunicable diseases: estimates and projections. World Health Stat Q, 41(3-4), 255-266.

Pobee, J.O., Larbi, E.B., Belcher, D.W., Wurapa, F.K., \& Dodu, S.R. (1977). Blood pressure distribution in a rural Ghanaian population. Trans R Soc Trop Med Hyg, 71, 6672.

Psaty, B.M., Lumley, T., Furberg, C.D., Schellenbaum, G., Pahor, M., Alderman, M.H., Weiss, N.S. (2003). Health outcomes associated with various antihypertensive therapies used as first-line agents: a network metaanalysis. JAMA, 289(19), 2534-2544.

Santos et al., (2011). Non-communicable diseases in subSaharan Africa: what we know now. Int J Epidemiol.

Seedat, Y.K., Hackland, D.B., Mpontshane, J. (1981). The prevalence of hypertension in rural Zulus. A preliminary study. S Afr Med J, 60(1), 7-10.

Shaper, A.G., Wright, D.H., \& Kyobe, J. (1969). Blood pressure and body build in three nomadic tribes of northern Kenya. East Afr Med J, 46(5), 273-281.

United Nations. (2008, August). Political declaration of the high-level meeting of the General Assembly on the prevention and control of non-communicable diseases. New York: United Nations. Retrieved from http://www.ncdalliance.org/sites/default/files/rfiles /UN\%20HLM\%20Political\%20Declaration\%20Englis h.pdf

World Health Organization (2013). Global strategy on diet, physical activity and health. Geneva: WHO. Retrieved from

http://www.who.int/dietphysicalactivity/strategy/eb 11344/strategy_french_web.pdf

World Health Organization (2017). Obesity and overweight. $\quad$ Retrieved from http://www.who.int/gho/ncd/risk_factors/overweigh $\mathrm{t} / \mathrm{en} / 3$.

World Health Organization. (1998). Life in the 21st century, a perspective for all. Geneva: WHO; World Health Report. Retrieved from https://apps.who.int/iris/handle/10665/42065

World Health Organization. (2000). World Health reporthealth systems: improving Performance. Geneva: Retrieved from http://www.who.int/whr/2000/en/.

World Health Organization. (2013, March 15). Global status report on non-communicable diseases 2010-2011. Retrieved

from http://whqlibdoc.who.int/publications/2011/978924 0686458_eng.pdf

World Health Organization. (2018). Global strategy on diet, physical activity and health. Retrieved from http://www.who.int/dietphysicalactivity/strategy/eb 11344/9241592222/fr/4.Basdevant 